Goldschmidt2020 Abstract

\title{
Microbially mediated alteration of basaltic tephra from Surtsey volcano, Iceland
}

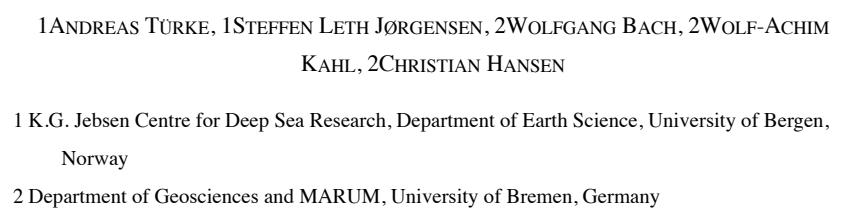

The significance of microbial activity in the oceanic crust, covering $60 \%$ of Earth's surface and potentially the largest and oldest of all ecosystems is almost unexplored. However, the existence of a deep biosphere and their potential to gain energy by exploiting redox reactions in the ocean crust is undisputed. Potential biosignatures like trace fossils in basalt glass have been detected in subseafloor basalts from various ages, but their occurrence is sparse and difficult to integrate into geological records of the deep biosphere in deep time.

Surtsey, the youngest of the islands of Vestmannaeyjar, is an oceanic volcano created by explosive basaltic eruptions during 1963-1967 off the southern coast of Iceland. In summer 2017, three cored boreholes were drilled through the active hydrothermal system of the volcano by the International Continental Scientific Drilling Program (ICDP) SUSTAIN Expedition 5059. They serve as samples of "zero-age" basalts and yield crucial insights into the first colonization of newly formed oceanic crust.

One of the boreholes has been equipped with a subsurface observatory dedicated to in-situ experiments for monitoring waterrock interactions and microbial processes in sterile, artificial basaltic glass. With temperatures ranging from 25 to $125^{\circ} \mathrm{C}$ the subsurface observatory provides a precise geothermal window into an active hydrothermal system and thus represents an exceptional natural laboratory for studying fluid-rock-microbe interactions at different temperatures and facilitates experimental validation of active submarine microbial processes at the fringe of functional life, about $121^{\circ} \mathrm{C}$.

The experiments have been retrieved after two years in the borehole in summer 2019. Additionally, ex-situ flow-through experiments with artificial basalt glass and microbes sampled from the Surtsey boreholes were used as inoculum and physical conditions in the Surtsey borehole were mimicked to test how microbial community structure and dissolution rates change in this broad temperature range.

First results from the in-situ and ex-situ basalt dissolution experiments will be presented with a focus on microbial community structures and alteration textures produced with and without the presence of microbes in basalt glass. 